\title{
Surgical management of diastolic heart failure after septal myectomy for obstructive hypertrophic cardiomyopathy
}

\author{
Daokun Sun, MD, MPH, ${ }^{a}$ Hartzell V. Schaff, MD, ${ }^{a}$ Rick A. Nishimura, MD, ${ }^{b}$ Jeffrey B. Geske, MD, ${ }^{b}$ \\ Joseph A. Dearani, MD, and Steve R. Ommen, MD ${ }^{b}$
}

\section{ABSTRACT}

Objective: Some patients with obstructive hypertrophic cardiomyopathy may remain limited after surgical relief of the subaortic obstruction. In this report, we describe experience in surgical management of patients with advanced diastolic heart failure symptoms after adequate transaortic septal myectomy for obstructive hypertrophic cardiomyopathy.

Methods: We identified adult patients who presented with heart failure symptoms after previous transaortic septal myectomy for obstructive hypertrophic cardiomyopathy and underwent repeat sternotomy for transapical myectomy to enlarge a small left ventricular cavity. Functional recovery after hospital dismissal was assessed through a questionnaire-based survey.

Results: Six patients with previous septal myectomy presented with New York Heart Association functional class III symptoms. Preoperative transthoracic Doppler echocardiography confirmed adequate relief of subaortic outflow tract obstruction with only trivial or mild mitral valve regurgitation; left atrial volume index was increased at $46 \mathrm{~mL} / \mathrm{m}^{2}$ (range, $44-47 \mathrm{~mL} / \mathrm{m}^{2}$ ). Following transapical myectomy, the left ventricular diameter was enlarged from $23 \mathrm{~mm}$ (range, 21-27 mm) to $29 \mathrm{~mm}$ (range, $27-31 \mathrm{~mm}$ ) at end-systole and from $40 \mathrm{~mm}$ (range, $38-42 \mathrm{~mm}$ ) to $43 \mathrm{~mm}$ (range, $42-50 \mathrm{~mm}$ ) at end-diastole. All the patients were alive after a median follow-up of 0.6 years (range, $0.4-3.5$ years), and 5 patients responded to a postoperative survey and indicated improvement in their heart condition compared with functional status before the repeat myectomy.

Conclusions: Patients with diastolic heart failure after septal myectomy for obstructive hypertrophic cardiomyopathy may present with systolic cavity obliteration due to excessive myocardial hypertrophy. Repeat transapical myectomy can enlarge the left ventricular chamber and augment the diastolic volume, which results in improved physical capacity and patient-perceived functional status. (JTCVS Techniques 2022;11:21-6)

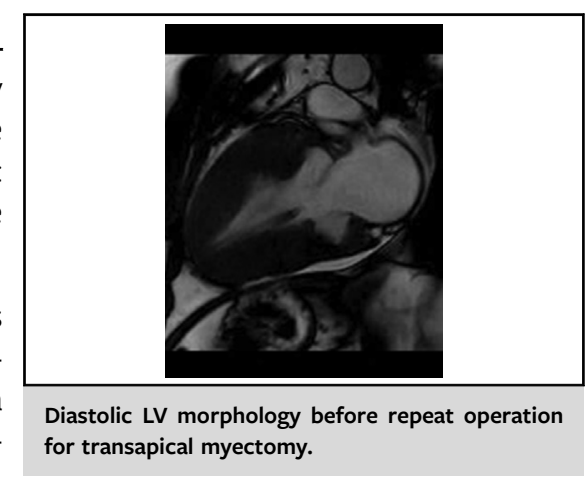

CENTRAL MESSAGE

Patients with diastolic heart failure after septal myectomy for obstructive hypertrophic cardiomyopathy may benefit from repeat transapical myectomy to enlarge the LV diastolic volume.

\section{PERSPECTIVE}

Patients with diastolic heart failure after septal myectomy for obstructive HCM may present with systolic cavity obliteration due to excessive myocardial hypertrophy. Repeat transapical myectomy can enlarge the LV chamber and augment the diastolic volume, which results in improved physical capacity and patientperceived functional status.

See Commentaries on pages 27 and 29.

$\checkmark$ Video clip is available online.

From the Departments of ${ }^{\mathrm{a}}$ Cardiovascular Surgery and ${ }^{\mathrm{b}}$ Cardiovascular Medicine, Mayo Clinic, Rochester, Minn.

Supported by the Paul and Ruby Tsai Family.

Received for publication July 19, 2021; accepted for publication Oct 25, 2021; available ahead of print Nov 1, 2021

Address for reprints: Hartzell V. Schaff, MD, Department of Cardiovascular Surgery, Mayo Clinic, 200 First St, SW, Rochester, MN 55905 (E-mail: schaff@mayo.edu). 2666-2507

Copyright $\odot 2021$ The Author(s). Published by Elsevier Inc. on behalf of The American Association for Thoracic Surgery. This is an open access article under the CC BY-NC-ND license (http://creativecommons.org/licenses/by-nc-nd/4.0/).

https://doi.org/10.1016/j.xjtc.2021.10.050
Approximately $70 \%$ of symptomatic patients with hypertrophic cardiomyopathy (HCM) have left ventricular outflow tract (LVOT) obstruction and may benefit from pharmacological treatment. ${ }^{1}$ If patients are severely limited and do not respond well to medical therapy, septal reduction by surgical myectomy may be recommended to eliminate or reduce dynamic LVOT obstruction and associated exertional symptoms. In previous studies, approximately $80 \%$ to $96 \%$ of patients reported improvement in heart failure 


$$
\begin{aligned}
& \text { Abbreviations and Acronyms } \\
& \text { AF }=\text { atrial fibrillation } \\
& \mathrm{EF}=\text { ejection fraction } \\
& \mathrm{HCM}=\text { hypertrophic cardiomyopathy } \\
& \mathrm{LV}=\text { left ventricular } \\
& \mathrm{LVOT}=\text { left ventricular outflow tract } \\
& \mathrm{TTE}=\text { transthoracic echocardiography }
\end{aligned}
$$

symptoms postprocedure. ${ }^{2-4}$ However, some patients remain limited despite relief of the subaortic obstruction.

Persistent symptoms after adequate relief of LVOT obstruction may result from residual midventricular obstruction, increased chamber stiffness due to increased muscle stiffness, or the burned-out phase of HCM. ${ }^{5-7}$ Limited physical capacity in patients with HCM and preserved systolic function may also be explained by increased chamber stiffness due to decreased left ventricular (LV) end diastolic volume as occurs in some patients with the apical HCM phenotype and patients with LV cavity obliteration. ${ }^{6,8,9}$ Such patients with nonobstructive HCM and diastolic heart failure may benefit from transapical myectomy to enlarge the LV diastolic volume as well as stroke volume and reduce end-diastolic pressure. ${ }^{10,11}$ In this report, we describe our experience in surgical management of patients with advanced heart failure symptoms after adequate transaortic septal myectomy for obstructive HCM.

\section{PATIENTS AND METHODS \\ Patient Population and Data Collection}

The study population included adult patients who presented with heart failure symptoms after previous transaortic septal myectomy for obstructive HCM and underwent repeat sternotomy for transapical myectomy to enlarge the small LV cavity. Hemodynamic parameters before the initial septal myectomy were measured on 2-dimensional Doppler echocardiography and were obtained from clinical notes available from the index hospitalization. Hemodynamic parameters evaluated before and immediately after the repeat operation was collected from the electronic health record and our internally maintained cardiovascular surgery database. Functional recovery after hospital dismissal was assessed through a questionnairebased survey initiated in October 2020. Patients were invited to report the extent of exertional symptoms postprocedure. Survey questions inquiring about level of physical activity and self-rated improvement in cardiac function included "Please mark the statement(s) that describe your level of physical activity" (answers included 1. Not limited, 2. Limited by something other than my heart, and 3. Limited by my heart) and "Compared with your heart condition before surgery, how much improvement in your heart function do you feel since your surgery" (answers included 1. A lot, 2. Quite a bit, 3. Some, 4. A little, and 5. Not at all). This study was approved by the Mayo Clinic Institutional Review Board (No. 21-003741, approved May 6, 2021). All patients consented and authorized use of their medical information for clinical research.

\section{Operative Details}

The transapical approach to myectomy has been detailed previously. ${ }^{10,11}$ In brief, operations were performed through a standard secondary median sternotomy, and all patients were placed on cardiopulmonary bypass with central aortic cannulation. After dissection of the heart from surrounding adhesion and cardioplegic arrest, an apical ventriculotomy was made far enough lateral to the left anterior descending artery to allow closure without vessel compromise. The anterolateral and posteromedial papillary muscles were identified and protected, and septal resection was initiated along the distal ventricular septum and extended from the apical area cephalad. We extended the myectomy proximally to the point where we could easily identify the previous subaortic resection. Additional excision of hypertrophied muscle was removed anteriorly, and significantly hypertrophied papillary muscles were shaved where appropriate to minimize risk of midventricular obstruction. In 1 patient who had prior mitral valve replacement, the hypertrophied papillary muscles were excised to augment ventricular cavity volume. ${ }^{12}$

\section{RESULTS}

\section{Patient Characteristics}

Median age of the 6 patients ( 3 women) with HCM who underwent transapical myectomy was 46 years (range, 3851 years), and the median (interquartile range [IQR]) age at initial operation was 33 years (IQR, 32-38 years) (Table 1). The median interval between the index operation and the repeat myectomy was 7.1 years (IQR, 3.6-9.6 years). Three of the 6 patients underwent the index operation at our clinic. The repeat myectomy procedures were performed between March 2013 and August 2020, with more than half $(n=4)$ performed during 2020. At the time of evaluation for repeat operation, all the patients had New York Heart Association functional class III symptoms; presenting complaints included exertional dyspnea $(\mathrm{n}=6)$, fatigue $(\mathrm{n}=4)$, and/or chest tightness $(\mathrm{n}=3)$. Three patients aged 49, 51, and 55 years had a history of atrial fibrillation (AF) before transapical myectomy; all of them were women, and all had persistent AF. Two patients underwent concomitant pulmonary vein isolation, and the left atrial appendage was ligated in 1 patient.

\section{Hemodynamic Parameters Before Index Transaortic Septal Myectomy}

Hemodynamic data before the initial operation were available for 5 patients. The median (IQR) septal thickness was $21 \mathrm{~mm}$ (IQR, 20-22 mm), and the left ventricle was hyperdynamic in most patients (ejection fraction $[\mathrm{EF}], 75 \%$ (IQR, 71\%-75\%). Resting LVOT gradient was $50 \mathrm{~mm} \mathrm{Hg}$ (IQR, 39-77 $\mathrm{mm} \mathrm{Hg}$ ), and the provoked LVOT gradient ranged from 56 to $104 \mathrm{~mm} \mathrm{Hg}(\mathrm{n}=3)$. Mitral valve regurgitation was mild in 3 patients and moderate in the other 2 . Imaging tests for comparison of cardiac morphology before the initial and the repeat myectomy were available in 3 patients as shown in the Video 1. Small left ventricle chamber size was not appreciated at the time of initial myectomy in any of the patients.

\section{Hemodynamic Parameters During Repeat Transapical Myectomy}

Figure 1 and Figure 2 show the LV morphology during systole and diastole for each of the 6 patients before 
TABLE 1. Characteristic features of the 6 patients

\begin{tabular}{|c|c|c|c|c|c|c|c|c|c|c|c|}
\hline \multirow[b]{2}{*}{ Patient } & \multirow[b]{2}{*}{ Sex } & \multicolumn{3}{|c|}{ Index transaortic myectomy } & \multirow[b]{2}{*}{ Interval (y) } & \multicolumn{6}{|c|}{ Repeat transapical myectomy } \\
\hline & & $\begin{array}{c}\text { Age } \\
(\mathbf{y})\end{array}$ & $\begin{array}{c}\text { Septal } \\
\text { thickness } \\
(\mathbf{m m})\end{array}$ & $\begin{array}{c}\text { EF } \\
(\%)\end{array}$ & & $\begin{array}{c}\text { Age } \\
(y)\end{array}$ & $\begin{array}{l}\mathbf{E F} \\
(\mathbf{y})\end{array}$ & $\mathbf{A F}$ & $\begin{array}{c}\text { Preoperative } \\
\text { LVEDD }(\mathbf{m m})\end{array}$ & $\begin{array}{l}\text { Postoperative } \\
\text { LVEDD (mm) }\end{array}$ & $\begin{array}{c}\text { Functional } \\
\text { improvement }^{*}\end{array}$ \\
\hline 1 & Male & 22 & 45 & 80 & 2 & 24 & 84 & $\mathrm{~N}$ & 30 & 43 & Unknown \\
\hline 2 & Male & 33 & 21 & 75 & 3 & 37 & 76 & $\mathrm{~N}$ & 41 & 52 & Some \\
\hline 3 & Female & 46 & 20 & 75 & 5 & 51 & 65 & $\mathrm{Y}$ & 38 & 43 & A lot \\
\hline 4 & Male & 33 & 18 & 68 & 9 & 42 & 70 & $\mathrm{~N}$ & 50 & 53 & A lot \\
\hline 5 & Female & 39 & I & I & 10 & 49 & 67 & $\mathrm{Y}$ & 38 & 42 & Some \\
\hline 6 & Female & 31 & 22 & 71 & 24 & 55 & 63 & Y & 42 & 41 & Some \\
\hline
\end{tabular}

$E F$, Ejection fraction; Interval, interval years between index septal myectomy and repeat transapical myectomy; $A F$, atrial fibrillation; $L V E D D$, left ventricular end-diastolic dimension. *Functional improvement was defined as the extent of functional improvement from survey results as described in the Methods.

transapical myectomy. None of the patients had residual LVOT obstruction at the time of repeat operation. On preoperative transthoracic echocardiography (TTE), the median LV diameter was $23 \mathrm{~mm}$ (IQR, 21-27 mm) at end-systole and $40 \mathrm{~mm}$ (IQR, 38-42 $\mathrm{mm}$ ) at end-diastole. Systolic function of the left ventricle was at or above the upper range of normal (EF, 69\%; IQR, 66\%-75\%). The stroke volume index was $43 \mathrm{~mL} / \mathrm{m}^{2}$ (IQR, 34-46 $\mathrm{mL} / \mathrm{m}^{2}$ ) and the cardiac index was $2.8 \mathrm{~L} / \mathrm{min} / \mathrm{m}^{2}$ (IQR, 2.4-3.3 L/min $/ \mathrm{m}^{2}$ ). Mitral valve regurgitation was mild in all patients except 1 , in whom the regurgitation was trivial. The median left atrial volume index, however, was $46 \mathrm{~mL} / \mathrm{m}^{2}$ (IQR, 44-47 mL/ $\mathrm{m}^{2}$ ) and an apical pouch was identified and repaired in 2 patients.

Postoperatively, the LVEF on TTE decreased to $64 \%$ (IQR, 62\%-65\%) before hospital dismissal. The LV endsystolic diameter was enlarged to $29 \mathrm{~mm}$ (IQR, 27$31 \mathrm{~mm}$ ), and the LV end-diastolic diameter was $43 \mathrm{~mm}$ (IQR, 42-50 mm). The extent of mitral valve regurgitation remained mild in 3 patients and was reduced to trivial in the other 3 .

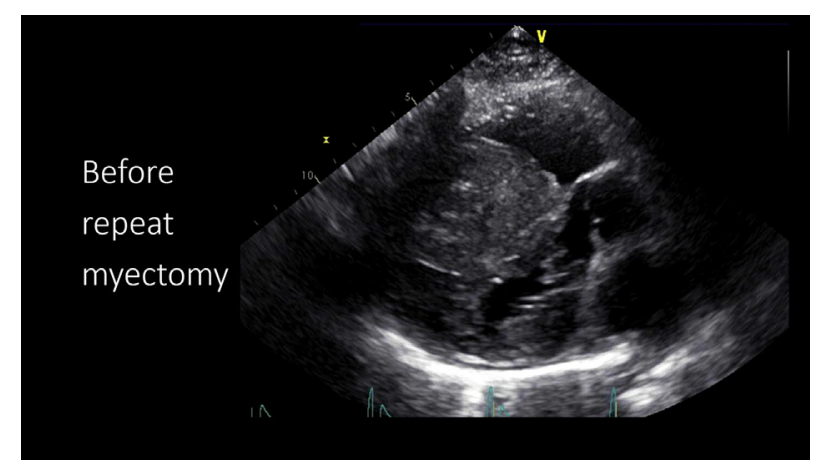

VIDEO 1. Comparison of cardiac morphology before the initial and the repeat myectomy available in 3 patients. Video available at: https://www. jtcvs.org/article/S2666-2507(21)00744-6/fulltext.

\section{Surgical Outcomes and Functional Recovery}

Surgical specimens were examined by cardiovascular pathologists as described previously. ${ }^{13}$ The median weight of muscle specimens was 9.8 g (IQR, 9.2-13.6 g). Myocyte hypertrophy was moderate in 1 patient and severe in the other 5. Four patients were found to have moderate or severe interstitial fibrosis, and in the other 2 patients, interstitial fibrosis was mild. No coexisting infiltrative pathologies were identified.

The median crossclamp time for the repeat operation was 26 minutes (IQR, 18-37 minutes) and the median cardiopulmonary bypass time was 46 minutes (IQR, 29-59 minutes). Patients stayed in the hospital for a median of 6.0 days (IQR, 6.5-7.8 days). No patient had sternal wound infection, reoperation for bleeding, pneumonia, renal failure, or permanent pacemaker implantation during the hospital stay postprocedure.

At a median follow-up of 0.6 years (IQR, 0.4-3.5 years), all the patients were alive. Five patients responded to the survey described above. Four of these 5 patients were surveyed 2 to 8 months after the transapical myectomy. Compared with the functional status before the repeat myectomy, patients reported some $(\mathrm{n}=3)$ or a lot $(\mathrm{n}=2)$ of improvement in their heart condition postprocedure, but 2 patients remained limited with shortness of breath on walking 2 blocks or less. Overall, 1 patient reported no physical limitation, and another patient was limited by a noncardiac condition. In the other 3 patients, physical capacity was perceived to be limited by the heart; all of these patients had a preoperative history of persistent AF.

\section{DISCUSSION}

Septal myectomy is useful to relieve LVOT obstruction and improve both pulmonary hypertension and LV filling in patients with obstructive HCM. ${ }^{14-16}$ But reducing the basal septal thickness and associated LVOT obstruction may not improve health status in some patients with HCM. $^{2}$ In this report, we describe a cohort of patients with persistent or recurrent symptoms after conventional 

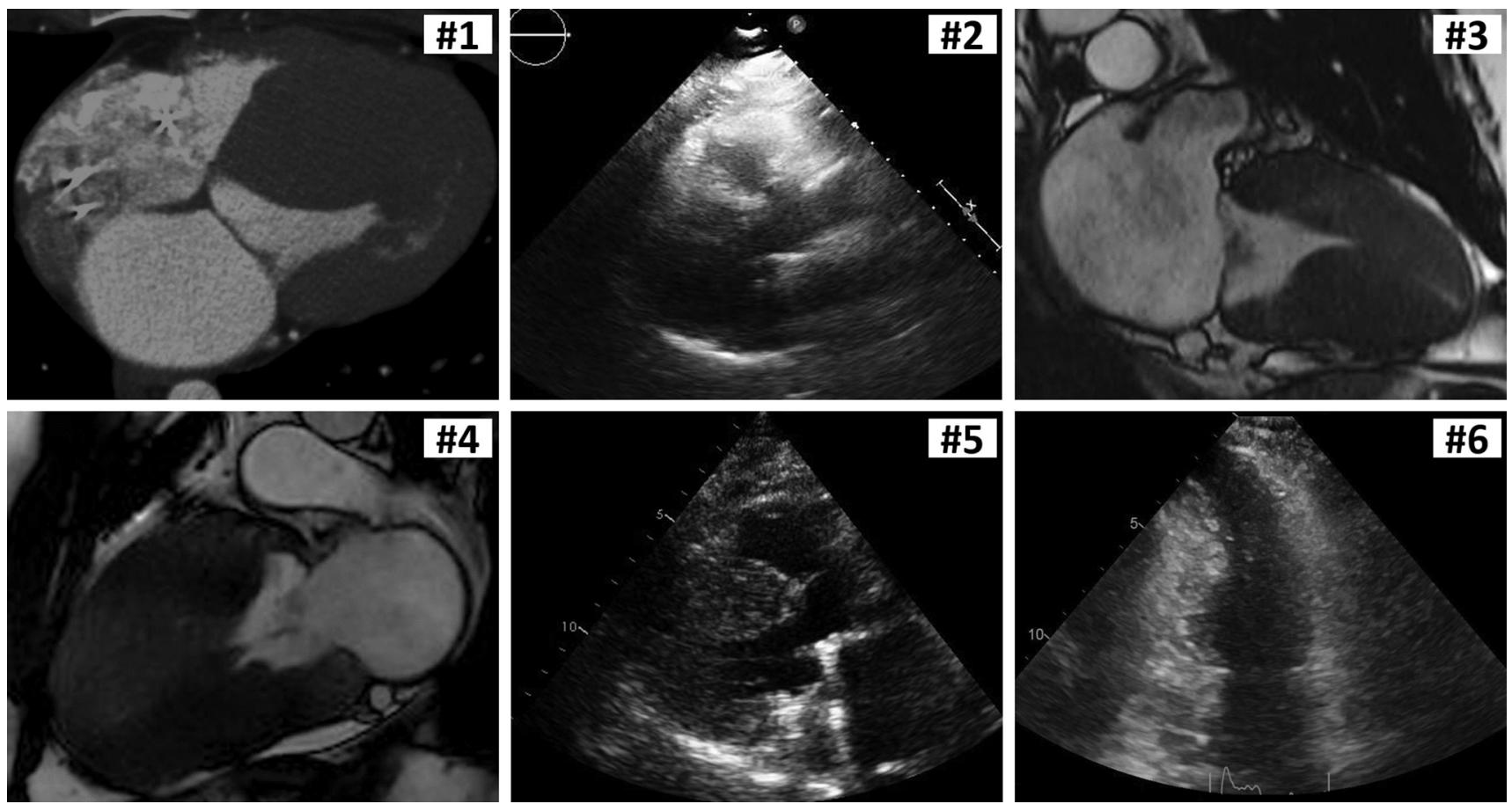

FIGURE 1. Left ventricular morphology during systole for each of the 6 patients before repeat transapical myectomy.

transaortic septal myectomy who appeared to have reduced LV volume due to excessive myocardial hypertrophy beyond the basal segment. Transapical myectomy to enlarge the LV cavity led to clinical improvement in the majority of patients.
Limited exercise capacity in many patients with $\mathrm{HCM}$ correlates with inability to increase LV stroke volume and cardiac output. ${ }^{17,18}$ Because patients with HCM generally have higher than normal LVEF, the ability to increase LV end-diastolic volume is important in augmentation of stroke
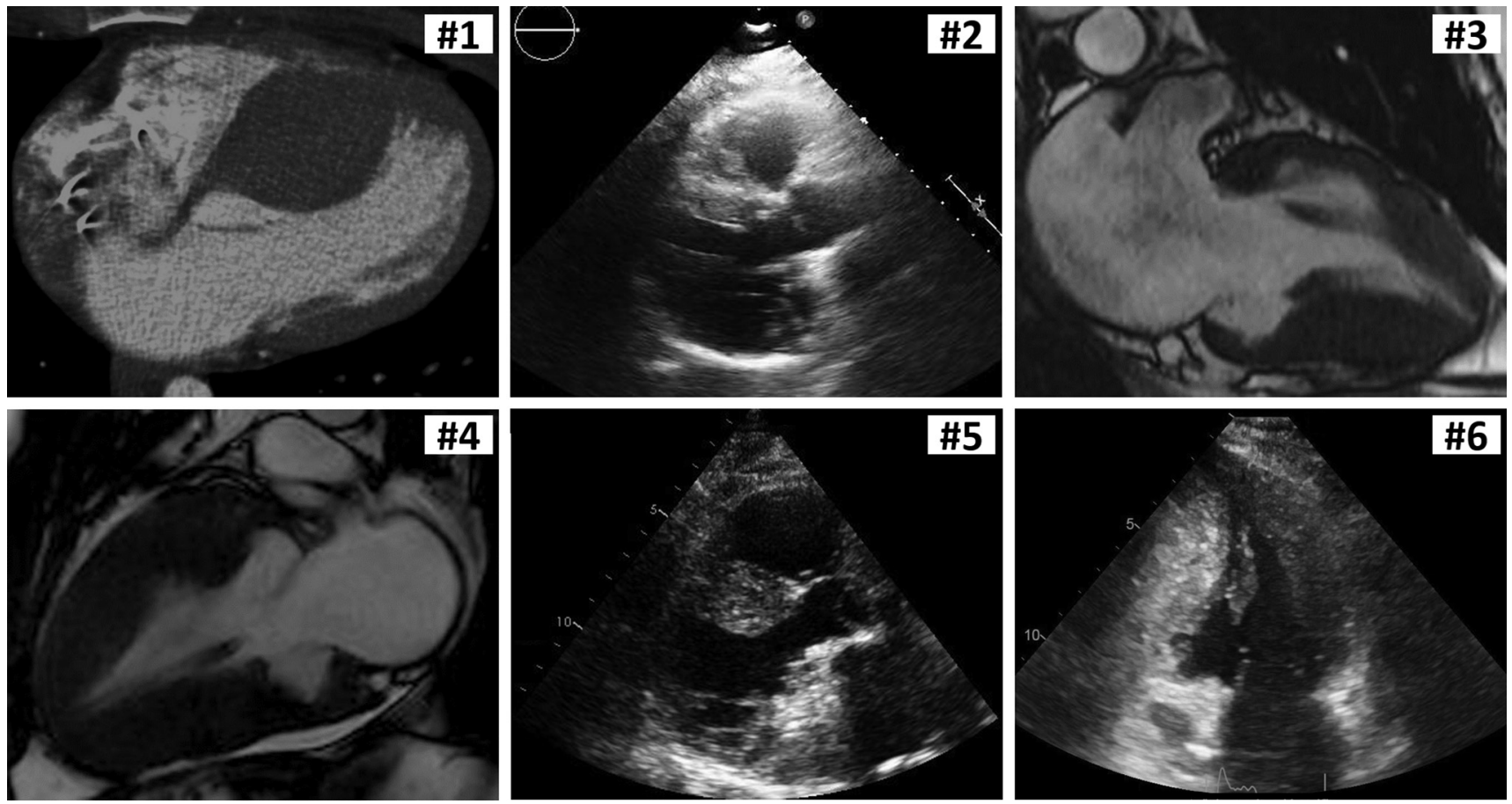

FIGURE 2. Left ventricular morphology during diastole for each of the 6 patients before repeat transapical myectomy. 
volume. ${ }^{18}$ However, increased myocardial hypertrophy in HCM may result in decreased LV diastolic volume, which leads to chamber stiffness reflected by a leftward shift of the LV diastolic pressure-volume curve compared with normal controls. ${ }^{19}$ Chamber stiffness may be influenced by intrinsic muscle stiffness, but this appears to be less important than the volume-mass effect in HCM. ${ }^{19}$ Nevertheless, pathological assessment of the surgical specimens suggested that the proportions of moderate or severe myocardial hypertrophy $(100 \%)$ and interstitial fibrosis $(66.7 \%)$ seemed slightly greater in the present study than previously reported in patients with obstructive $\mathrm{HCM}$ (myocardial hypertrophy $97.3 \%$ and interstitial fibrosis $32.4 \%),{ }^{13}$ and the influence of myocardial stiffness in patients with nonobstructive HCM remains to be elucidated.

Previously we reported that apical myectomy can augment LV stroke volume and improve symptoms in $76 \%$ to $98 \%$ of patients with nonobstructive HCM and diastolic heart failure. ${ }^{10,11}$ In agreement with previous findings, all patients in the present study reported self-perceived improvement in cardiac function. However, 3 female patients who had a preoperative history of persistent AF considered themselves to be limited by their hearts. Indeed, $\mathrm{AF}$ is a significant predictor of severe symptoms at clinical evaluation, and patients with nonobstructive HCM are more susceptible to AF than patients with the obstructive phenotype.$^{20}$ Klarich and colleagues ${ }^{21}$ found that the likelihood of having $\mathrm{AF}$ was 2.3 times as high at baseline and 1.8 times as high during follow-up in women with nonobstructive HCM. $^{21}$ The confounding effect of cardiovascular comorbidities on symptom improvement after myectomy needs further investigation.

Substantially compromised LV volume may not be apparent in some patients with obstructive HCM undergoing septal myectomy. Alternatively, late development of systolic cavity obliteration may reflect late LV remodeling. ${ }^{22}$ Progression of LV hypertrophy in HCM is usually reported in children and adolescents and anecdotally in adults. With up to 7 years of follow-up, Maron and colleagues $^{23}$ observed 6 to $23 \mathrm{~mm}$ increase in the LV wall thickness among 22 patients aged 4 to 15 years. ${ }^{23}$ In adult patients, Flett and colleagues ${ }^{24}$ reported a 47 -year-old male with progressively increased wall thickness from $12 \mathrm{~mm}$ to $18 \mathrm{~mm}$ during 6 years of follow-up, which was accompanied by a continuously elongated length of apical obliteration from $25 \mathrm{~mm}$ to $41 \mathrm{~mm} .{ }^{24}$ It should be noted that patients in our current report were considerably younger at index operation in comparison to the overall population who have undergone transaortic septal myectomy for obstructive HCM at our clinic. ${ }^{25}$ It appears that the chance of LV remodeling is greater in younger adults with HCM compared with older patients.

In other patients, examination of the cardiac images suggested that a small LV cavity was present at the time of the index transaortic septal myectomy. In the retrospective review, we observed apposition of the papillary muscles and the hypertrophied interventricular septum in the distal LV chamber during systole, but obstructive gradients at the mid ventricle were barely detectable. In contrast to the typical midventricular variant of HCM, maximum instantaneous midventricular gradients at the time of myectomy, if present, were $<30 \mathrm{~mm} \mathrm{Hg}$ with provocation in all the patients in this report. The small LV cavity was recognized in all but 1 patient on TTE before transapical myectomy, and LV end-diastolic diameter was below the lower limit of normal range in 4 patients. Indeed, given the apical predominant hypertrophy of this cohort and known heterogeneous distribution of LV hypertrophy in HCM, LV end-diastolic diameter alone may not be sufficient to define a small LV cavity. Furthermore, imaging the apex is sometimes challenging through standard echocardiogram. Hence, advanced imaging techniques such as cardiac magnetic resonance imaging or cardiac computed tomography may be useful to appreciate the anatomical structure of the distal LV and aid in the measurement of LV volume.

Arguably, heart failure symptoms in most patients with obstructive HCM can be more readily ascribed to LVOT obstruction than small LV cavity. However, if abnormalities in the stroke volume and/or diastolic function can be simultaneously recognized as a result of excessive myocardial hypertrophy, prophylactic LV enlargement in addition to the subaortic septal resection may be beneficial. ${ }^{26}$

Several limitations of the current report should be acknowledged. First, this patient review is subject to the limitations and biases commonly present in every retrospective study. Patients included in this series underwent repeat transapical myectomy before the study was initiated. Therefore, available cardiac evaluation and imaging tests were limited only if clinically necessary. Postoperative followup was conducted through direct mail and phone contact. The response rate can be influenced by patient characteristics, geographical differences, and changes in phone number or physical location. LV volumes are difficult to quantify in patients with the phenotypes we have described. Linear measurement of the LV dimension on echocardiography is completed at the tips of mitral leaflets, ${ }^{27}$ which may not capture the extent of volume obliteration near the apex. Identification of LV cavity obliteration is largely subjective but is well recognized. ${ }^{7,28}$ Estimated stroke volume and cardiac index at rest may not provide comprehensive insight into the mechanism of physical limitation. Our observations are limited by the small sample in this series, but the experience has led to increasing use of combined transaortic and transapical myectomy in our practice and may be useful to other surgeons who encounter patients with obstructive HCM. This study illustrates a newly recognized patient cohort who may benefit from transapical myectomy after standard transaortic septal myectomy. 
The majority of patients underwent the repeat procedure within a year before this study was initiated, which results in limited length of follow-up.

\section{CONCLUSIONS}

Patients with diastolic heart failure after septal myectomy for obstructive HCM may present with reduced LV stroke volume and systolic cavity obliteration due to increased chamber stiffness with excessive myocardial hypertrophy. Repeat transapical myectomy can enlarge the LV chamber and augment the diastolic volume, which results in improved physical capacity and patient-perceived functional status.

\section{Conflict of Interest Statement}

The authors reported no conflicts of interest.

The Journal policy requires editors and reviewers to disclose conflicts of interest and to decline handling or reviewing manuscripts for which they may have a conflict of interest. The editors and reviewers of this article have no conflicts of interest.

\section{References}

1. Maron MS, Olivotto I, Zenovich AG, Link MS, Pandian NG, Kuvin JT, et al. Hypertrophic cardiomyopathy is predominantly a disease of left ventricular outflow tract obstruction. Circulation. 2006;114:2232-9.

2. Nguyen A, Schaff HV, Ommen SR, Gersh BJ, Dearani JA, Geske JB, et al. Late health status of patients undergoing myectomy for obstructive hypertrophic cardiomyopathy. Ann Thorac Surg. 2021;111:1867-75. https://doi.org/10.1016/j. athoracsur.2020.09.011

3. Wells S, Rowin EJ, Boll G, Rastegar H, Wang W, Maron MS, et al. Clinical profile of nonresponders to surgical myectomy with obstructive hypertrophic cardiomyopathy. Am J Med. 2018;131:e235-9.

4. Nishimura RA, Seggewiss H, Schaff HV. Hypertrophic obstructive cardiomyopathy: surgical myectomy and septal ablation. Circ Res. 2017;121:771-83.

5. Yacoub MH, Olivotto I, Cecchi F. "End-stage" hypertrophic cardiomyopathy: from mystery to model. Nat Clin Pract Cardiovasc Med. 2007;4:232-3.

6. Cho YH, Quintana E, Schaff HV, Nishimura RA, Dearani JA, Abel MA, et al. Residual and recurrent gradients after septal myectomy for hypertrophic cardiomyopathy-mechanisms of obstruction and outcomes of reoperation. J Thorac Cardiovasc Surg. 2014;148:909-16.

7. Wigle ED, Sasson Z, Henderson MA, Ruddy TD, Fulop J, Rakowski H, et al. Hypertrophic cardiomyopathy. The importance of the site and the extent of hypertrophy. A review. Prog Cardiovasc Dis. 1985;28:1-83.

8. Matsubara K, Nakamura T, Kuribayashi T, Azuma A, Nakagawa M. Sustained cavity obliteration and apical aneurysm formation in apical hypertrophic cardiomyopathy. J Am Coll Cardiol. 2003;42:288-95.

9. Rakowski H, Carasso S. Quantifying diastolic function in hypertrophic cardiomyopathy. Circulation. 2007;116:2662-5.

10. Schaff HV, Brown ML, Dearani JA, Abel MD, Ommen SR, Sorajja P, et al. Apical myectomy: a new surgical technique for management of severely symptomatic patients with apical hypertrophic cardiomyopathy. J Thorac Cardiovasc Surg. 2010;139:634-40.

11. Nguyen A, Schaff HV, Nishimura RA, Geske JB, Dearani JA, King KS, et al Apical myectomy for patients with hypertrophic cardiomyopathy and advanced heart failure. J Thorac Cardiovasc Surg. April 5, 2019 [Epub ahead of print]. https://doi.org/10.1016/j.jtcvs.2019.03.088

12. Sun D, Schaff HV, Gersh BJ, Borlaug BA. Nonobstructive hypertrophic cardiomyopathy in a patient with mitral prosthesis. Ann Thorac Surg. 2021;111: e429-32. https://doi.org/10.1016/j.athoracsur.2020.09.059

13. Cui H, Schaff HV, Lentz Carvalho J, Nishimura RA, Geske JB, Dearani JA, et al. Myocardial histopathology in patients with obstructive hypertrophic cardiomyopathy. J Am Coll Cardiol. 2021;77:2159-70.

14. Monteiro PF, Ommen SR, Gersh BJ, Dearani JA, Schaff HV, Nishimura RA, et al. Effects of surgical septal myectomy on left ventricular wall thickness and diastolic filling. Am J Cardiol. 2007;100:1776-8.

15. Tower-Rader A, Furiasse N, Puthumana JJ, Kruse J, Li Z, Andrei A-C, et al. Effects of septal myectomy on left ventricular diastolic function and left atrial volume in patients with hypertrophic cardiomyopathy. Am J Cardiol. 2014;114: $1568-72$.

16. Ong KC, Geske JB, Hebl VB, Nishimura RA, Schaff HV, Ackerman MJ, et al. Pulmonary hypertension is associated with worse survival in hypertrophic cardiomyopathy. Eur Heart J Cardiovasc Imaging. 2016;17:604-10.

17. Frenneaux MP, Porter A, Caforio AL, Odawara H, Counihan PJ, McKenna WJ. Determinants of exercise capacity in hypertrophic cardiomyopathy. J Am Coll Cardiol. 1989;13:1521-6.

18. Lele SS, Thomson HL, Seo H, Belenkie I, McKenna WJ, Frenneaux MP. Exercise capacity in hypertrophic cardiomyopathy. Role of stroke volume limitation, heart rate, and diastolic filling characteristics. Circulation. 1995;92: 2886-94.

19. Gaasch WH, Levine HJ, Quinones MA, Alexander JK. Left ventricular compliance: mechanisms and clinical implications. Am J Cardiol. 1976;38: 645-53.

20. Siontis KC, Geske JB, Ong K, Nishimura RA, Ommen SR, Gersh BJ. Atrial fibrillation in hypertrophic cardiomyopathy: prevalence, clinical correlations, and mortality in a large high-risk population. J Am Heart Assoc. 2014;3: e001002.

21. Klarich KW, Attenhofer Jost CH, Binder J, Connolly HM, Scott CG, Freeman WK, et al. Risk of death in long-term follow-up of patients with apical hypertrophic cardiomyopathy. Am J Cardiol. 2013;111:1784-91.

22. Maron BJ, Spirito P. Implications of left ventricular remodeling in hypertrophic cardiomyopathy. Am J Cardiol. 1998;81:1339-44.

23. Maron BJ, Spirito P, Wesley Y, Arce J. Development and progression of left ventricular hypertrophy in children with hypertrophic cardiomyopathy. $N$ Engl $J$ Med. 1986;315:610-4.

24. Flett AS, Maestrini V, Milliken D, Fontana M, Treibel TA, Harb R, et al. Diagnosis of apical hypertrophic cardiomyopathy: T-wave inversion and relative but not absolute apical left ventricular hypertrophy. Int J Cardiol. 2015;183: $143-8$

25. Meghji Z, Nguyen A, Fatima B, Geske JB, Nishimura RA, Ommen SR, et al. Survival differences in women and men after septal myectomy for obstructive hypertrophic cardiomyopathy. JAMA Cardiol. 2019;4:237-45.

26. Hang D, Schaff HV, Ommen SR, Dearani JA, Nishimura RA. Combined transaortic and transapical approach to septal myectomy in patients with complex hypertrophic cardiomyopathy. J Thorac Cardiovasc Surg. 2018;155:2096-102.

27. Lang RM, Badano LP, Mor-Avi V, Afilalo J, Armstrong A, Ernande L, et al. Recommendations for cardiac chamber quantification by echocardiography in adults: an update from the American Society of Echocardiography and the European Association of Cardiovascular Imaging. Eur Heart J Cardiovasc Imaging. 2015;16: 233-71.

28. Kim H, Park J-H, Won K-B, Yoon H-J, Park H-S, Cho Y-K, et al. Significance of apical cavity obliteration in apical hypertrophic cardiomyopathy. Heart. 2016; 102:1215-20.

Key Words: hypertrophic cardiomyopathy, diastolic heart failure, repeat operation, transapical myectomy 